\title{
Conceptualizing and Capturing Outcomes of Environmental Cleanup at Contaminated Sites
}

\author{
Brittany Kiessling and Keely Maxwell
}

\begin{abstract}
Our article analyzes interdisciplinary literature within the social sciences on outcomes of environmental cleanups at Superfund, brownfield, and other contaminated sites. By focusing on postremediation sites and outcomes, we expand the understanding of the sociopolitical life of contaminated sites over time. First, we examine the technoscientific practices of how scientists and environmental managers seek to make cleanup outcomes legible and meaningful. Next, we engage with a wider array of literature on pollution/toxicity, uncovering circular temporalities in cleanup processes along with continuities in pollution/toxicity and in political struggle. Finally, we examine the social worlds of postremediation landscapes, drawing attention to how cleanups create new relationships among people, history, and nature. In conclusion, we identify areas of opportunity for these insights to inform the conceptualization and evaluation of cleanup outcomes in ways that better incorporate the complex dynamics of postremediation social worlds.
\end{abstract}

KEYWORDS: brownfields, cleanup, environmental management, evaluation, pollution/ toxicity, remediation, Superfund, time

At the intersection of environmental justice, science and technology studies (STS), and political ecology, there is an emerging area of inquiry concerning environmental cleanups at contaminated sites (Beckett and Keeling 2019; Clapp et al. 2016; Dillon 2014; Kiessling et al. 2021; Lehigh et al. 2020; Little 2014; Maxwell et al. 2018). This research highlights the social construction of risk and risk assessments (Checker 2007) and the long legacies of intersecting environmental injustices (Dillon 2014; Fletcher 2002; Hoover 2017). It serves as a call to action for the environmental management community by demonstrating the necessity and challenges of community engagement (Cruz 2019; Lehigh et al. 2020), the importance of building trust with surrounding community members (Ando 2018; Metcalf et al. 2015), and the emotional and power dimensions of risk mitigation (Little 2012,2013). In this article, we examine an essential piece of this area of inquiry on the "postremediation" stage of cleanups, after sites have been designated ready for reoccupation, redevelopment, and reuse. We engage research from across the social sciences on three key questions: What are the technoscientific practices of evaluating cleanup outcomes? What are the social worlds of postremediation landscapes? And how might outcome measures better capture the complex material and social entanglements of these social worlds?

Postremediation is a time of transition for contaminated sites and affected communities. It entails distinct governance, property rights, natural resource use, scientific measurements, sociochemical relations, and environmental management actions. We are also in a time of the 
Anthropocene, with anthropogenic influences on many of our planet's biogeophysical systems (Crutzen 2006), which leads to the question of what "clean" means in a "permanently polluted world" (Liboiron et al. 2018: 332). If we take chemicals as existing within broader social and affective relations (Murphy 2017; Nading 2020; Shapiro and Kirksey 2017), additional questions arise over how these relationships change after contaminants are removed, treated, or contained in a cleaned-up site. As such, specific attention to postremediation brings added depth to our understanding of the sociopolitical life of contaminated sites and pollution/toxicity over time.

Our article explores how the political and social relationships, technoscientific practices of environmental management and monitoring, and bodily and affective entanglements with pollution/toxicity contribute to worldmaking within and about postremediation landscapes. We review how literature from the social sciences analyzes cleanup outcomes and measures of these outcomes. We also bring these works on outcomes together with critical anthropological, STS, sociological, and geographical literature on pollution/toxicity in order to unpack how outcomes are conceptualized and evaluated. First, we begin the discussion by analyzing the technoscientific practices currently associated with measuring environmental cleanup outcomes. We review research that highlights how cleanup outcome measures are embedded in broader politics of expertise. Second, we underscore how measures found in the literature focus largely on economics, leaving out important pieces about understanding postremediation social worlds. Third, we discuss how the practices of measuring cleanup levels and endpoints reveal the circular temporalities of cleanups-that is, how a future imaginary for the site effectively reaches back in time to establish cleanup levels and remedies, which then shape postremediation land use. We situate cleanups within continuities in political struggle and continuities in suffering for affected communities and populations. Fourth, we examine the creation of new social worlds, including changing landscapes of institutional control, care for people's bodies and emotions, and how history and nature intertwine in how postremediation landscapes are represented and managed. Finally, we end the article with a discussion of how social scientists and environmental managers can move forward in applying sociocultural insights to cleanup outcomes. We query how social scientists might help formulate a broader "sociotechnical imaginary" (Jasanoff 2015) for postremediation social worlds and how they might contribute to its enactment. We speculate about whether evaluating outcomes can break out of a self-reinforcing politics of expertise (Choy 2005) to open up space for new ways of knowing, thus potentially contributing to worldmaking that enables socially and environmentally just postremediation social worlds (Beckett and Keeling 2019; Hoover 2020; Nading 2020; Tsosie 2015).

\section{Methods}

The following discussion builds upon an extensive literature review $(n=97)$ of social science research on environmental cleanups of contaminated sites (for details on methodology, see Maxwell et al. 2018). By environmental cleanup, we refer to technical action undertaken as part of a regulatory framework intended to reduce environmental and health risks in contaminated sites through remediation or removal remedies, including, potentially, during emergency responses. Our terminology of cleanups is purposely broad to allow for comparison across regulatory programs, types of contamination, and national and international contexts. We are also shaped by our standpoint as anthropologists working at the US Environmental Protection Agency (EPA). Our language is shaped by the EPA's specifically defined terminology, regulatory frameworks, and distinction among cleanup stages and contaminated sites (i.e., Superfund, brownfields). Cleanups of contaminated sites go through several technical stages, which differ depending on 
site type, institutional context, and regulatory context. Generally, these steps involve identifying and characterizing contamination, establishing cleanup levels of allowable concentrations of contamination for reuse, and selecting remedial or removal remedies to remove, contain, or treat contamination and restrict exposure pathways. Upon completion of these remedies, the site moves into "postremediation," when sites can be reoccupied, reused, or redeveloped (see Maxwell et al. 2018 for a more complete discussion of cleanup types, activities, and stages).

Our 2018 article conducted a qualitative thematic analysis, or critical review, to analyze the literature (Grant and Booth 2009; Hart 1998; Thomas and Harden 2008). Inclusion criteria were that sources must (1) use theories and/or methods from a social science discipline; (2) address one or more social dimensions of environmental cleanup; (3) be published after 1991; (4) meet quality control criteria; and (5) be written in English. Our review found a relatively narrow range of existing measures of cleanup outcomes, largely in the economics literature.

For the current article, we updated the original search to capture advancements in the scholarly literature. We also conducted a more focused search to ascertain how researchers from a variety of social science disciplines conceptualize and assess cleanup outcomes. We conducted keyword searches for peer-reviewed journal articles in Anthrosource and Web of Science, using search terms such as "measuring success," "evaluating Superfund," and "landscape and remediation." This search used the inclusion criteria listed above with the additional criterion that the article needed to address postremediation of contaminated sites or outcomes of other environmental management endeavors. We added references that met these criteria from article bibliographies or reviewer suggestions for a total of 92 articles. Our analysis placed these articles in conversation with other works on pollution/toxicity from anthropology, STS, geography, and sociology.

\section{Themes in the Literature}

\section{Technoscientific Practices of Measuring Outcomes}

In regulatory site management practices, demarcating when a site is in remediation and when it is in postremediation relies on the monitoring of different environmental media. These measurements are expressed in quantitative and highly specific ways, such as dose radioactivity levels in soil or parts per billion of PCBs in groundwater. These articles show how technoscientific practices of measuring cleanup progress privilege the quantitative and the specific. Measures of oil spill cleanup endpoints intended to capture both social and environmental outcomes, for example, were centered entirely on physical characteristics: oil stickiness, thickness, and bleeding (Fejes et al. 2008). Measuring physical characteristics, however, does not explicitly connect environmental changes resulting from oil spill cleanups to societal outcomes such as cleanup worker health or fishing livelihoods. The process of measurement and quantification can itself be atomizing of the environment. Analysis of ocean ecosystem conditions after the Deepwater Horizon oil spill show that "the environment came apart and then was put back together" (Bond 2013: 695) so it could be accurately measured using specialized instrumentation. It was the process of this atomization, as much as the results of environmental measurements, that shaped social actors' perceptions of what constitutes "the environment" of the Gulf (Bond 2013).

Sociopolitical conflicts do arise over "how clean is clean," that is, the establishment of cleanup levels and interpretations of what they mean (Gephart 2003; Hoffman 1995; Jorgensen 2016). At one Superfund National Priorities List site in New Jersey, EPA and community groups defined "clean" differently: the EPA interpreted it to mean that the site was harmless to human health; community groups interpreted it to mean that all toxic chemicals should be removed from the 
site (Van Horn and Chilik 1988). Suggestions from the environmental management social science literature for resolving conflicts over cleanup levels tend to focus on stakeholder education about risk (Jorgensen 2016). This strategy reflects an "information poverty" narrative (Delbourne and Galusky 2011), and may be incomplete for reasons detailed below.

STS studies illuminate how technoscientific practices of measuring and monitoring environmental changes after cleanups are embedded in broader epistemic politics (Bond 2013) or knowledge politics (Frickel and Vincent 2007). While these works do not all directly engage with postremediation, they do help further explain conflicts over levels and endpoints by shifting focus from "how clean is clean?" to "whose knowledge counts in determining clean?" After Hurricane Katrina, sampling and testing for potential contaminants in sediments and soils in New Orleans produced technically accurate measurements on a small scale yet uneven knowledge investments across the city, which as a whole generated ignorance as much as knowledge (Frickel 2012; Frickel et al. 2009). Disconnects between residents and scientists and ongoing mistrust were barriers to local voices being heard in postdisaster planning in New Orleans (Allen 2007). Citizen-science bucket brigades, personal exposure studies, oral histories, and diaries are other ways of knowing about how contaminated sites, toxicity, bodies, and social worlds interrelate (Clapp et al. 2016; Morello-Frosch et al. 2011; Nading 2020; Shapiro 2015; Tironi 2018). Yet during environmental cleanups, it is primarily technical expertise from environmental agencies, public health agencies, and contractors that informs decisions such as "how clean is clean?" and "when are sites clean?" (Beckett and Keeling 2019; Clapp et al. 2016; Kiessling et al. 2021; Shriver et al. 2008). A self-reinforcing politics of expertise (Choy 2005) is normalized, one that circumscribes expectations of what can and should be remediated, which in turn affects the environmental and social worlds of postremediation landscapes (Beckett and Keeling 2019; Hoover 2020; Tsosie 2015).

\section{Evaluating Societal Outcomes}

The techniques for evaluating societal outcomes of cleanups found by our review tell better stories about some contaminated site contexts and postremediation social worlds than they do about others. Most of these evaluation measures are grounded in economics, using hedonic pricing models to analyze changes in housing values in neighborhoods around contaminated sites. Economists also apply cost-benefit analyses by comparing societal benefits of cleanups, in the form of increased housing prices or tax revenue, to cleanup costs (Burger 2019; Burger et al. 2019; Greenstone and Gallagher 2008; Savchenko and Braden 2019). Hedonic modeling analyses indicate that environmental cleanups can have a positive effect on neighborhood housing prices (Chattopadhyay et al. 2005; Gamper-Rabindran and Timmins 2011, 2013; Guignet et al. 2018; Ketkar 1992; Mastromonaco and Maniloff 2018), but not always (Greenstone and Gallagher 2008; Kiel 1995). Changes in housing price are mediated by delays in cleanups, geographic distance from the site, existing neighborhood housing values, housing quality, exposure pathway, and information availability-all aspects of its social context (Guignet and Martinez-Cruz 2018; Lang and Cavanagh 2018; Messer et al. 2006; Savchenko and Braden 2019). Recent research has begun to parse out how different stages of cleanup (i.e., discovery, listing, remedy selection) contribute to positive or negative changes in housing price (Guignet and Martinez-Cruz 2018; Mastromonaco and Maniloff 2018). However, this body of work does not cover all types of cleanup situations equally. Superfund National Priority List sites in the United States have received the most attention (Maxwell et al. 2018) with more recent work on brownfields and leaking underground storage tank sites as well (Guignet et al. 2018; Guignet and Martinez-Cruz 2018; Lang and Cavanagh 2018). 
Economic and environmental measures of cleanup outcomes are largely disembodiedboth from people's actual bodies as well as from the social worlds of postremediation landscapes. They reflect whether housing prices rise or fall-but not who is in those homes. Yet race, ethnicity, gentrification, and urban development are inextricably linked to how neighborhood residents experience cleanups (Checker 2011; Clapp et al. 2016; Fletcher 2002; Gamper-Rabindran and Timmins 2011; Maantay and Maroko 2018). Existing measures tell us whether cleanup levels for recreational use have been achieved-but not who can access recreational areas. They do not explicitly engage with changes to social order, rules, relationships, values, property rights, or power dynamics. Measures of cleanup levels and outcomes are, by and large, colorblind, focusing on environmental concentrations in groundwater or soils rather than on Black or Brown bodies and communities. As such, they run the risk of erasing both local histories of environmental racism and local Black or Brown community connections with landscapes (Blanton 2011). More holistic, multidisciplinary frameworks and indicators for assessing how environmental cleanups impact lives and communities have been proposed in the literature. However, while a few case studies have applied proposed indicators to specific locales, such measures are not incorporated into cleanup practice. Even hedonic pricing is not routinely used in Superfund and brownfield management, as it requires specialized staff expertise, and resources such as real estate datasets.

\section{Circular Temporalities and Continuities}

Our analysis of the literature on measures reveals the circular temporalities of cleanup levels, remedies, and outcomes, particularly in the US regulatory context. Here, we use the term "circular temporalities" to refer to how, during cleanups, a "sociotechnical imaginary" (Jasanoff 2015) for the future of a site (i.e., whether it is to be residential, commercial, or industrial) effectively reaches back in time to inform cleanup levels and remedies. This in turn affects postremediation land use. Political struggles over toxicity reveal competing sociotechnical imaginaries of the future (Ahmann 2019). The environmental management pathway to realizing these imaginaries after remediation may involve transferring property rights or constraining natural resource use through institutional controls (Alexis-Martin and Malin 2017; McCaffrey 2018). As such, circular temporalities shape postremediation social worlds.

Circular temporality is also seen in how some brownfield sites, during site assessment, are found to not be contaminated at all-at least in concentrations and exposure pathways that warrant removal to reduce risks to human health. It is the possibility of future pollution discovery, the concern that future development might exacerbate future health risks, that leads to the site being characterized as a brownfield in the first place. These circular temporalities show that achieving cleanup outcomes is not a linear trajectory that runs clearly from start to finish. Rather, a cleanup process is iterative and can curl back on itself, making outcomes complicated to define and measure.

Insights from critical social science research on pollution/toxicity help explain differences in how social actors and institutions conceptualize and evaluate outcomes. By and large, this body of work does not directly engage with outcome measures or with postremediation as a discrete time period. Instead, it contextualizes the sociopolitical life of contaminated site cleanups within continuities - of political struggle, pollution/toxicity, and suffering. It interrogates their social and material entanglements. By looking backward in time, it illuminates how racial histories, colonial and postcolonial governance, industrial histories, and neoliberal development mediate the causes and consequences of pollution and its management (Ahmann 2019; Blanton 
2011; Fortun 2012; Little 2019; Roberts 2017; Williams 2001). It situates conflicts over cleaning up contaminated sites within enduring political struggles for racial equality, environmental justice, tribal sovereignty, and urban development (Checker 2011; Hird 2017; Hoover 2017; Lanari 2019; MacFarlane 2019; Newman 2011; Tsosie 2015; Williams 2001). These insights highlight how environmental cleanups may in fact reawaken or perpetuate inequalities (Beckett and Keeling 2019; Dillon 2014; Keeling and Sandlos 2017). For example, a brownfield redevelopment project that created a public park in Paris, France, was spurred on and intersected with neighborhood activism for racial and ethnic justice (Newman 2011). While the park was by many measures a success, its creation did not resolve these broader struggles. Instead, conflicts between locals and experts over competing visions for the park may have even reproduced social inequities within the cleanup process (Newman 2011).

Another aspect of continuities of struggle is the effect of the speed of contamination and the speed of cleanups on people's ability to mobilize. "Slow contamination," which can be interpreted as a form of "slow violence" (Ahmann 2018; Nading 2020), affected local struggles over a proposed waste incinerator in Baltimore, as "the steady stream of industrial projects and the gradual accumulation of toxics have germinated slowly" (Ahmann 2018: 146). The slowness and multiple sources of pollution make it difficult for activists to muster allies and support. Similarly, in Italy, contamination from petroleum refineries is made invisible in part by its slow nature (Benadusi 2018). By engaging with continuities in cleanup struggles, these articles illustrate the difficulties in achieving effective pollution management and positive postremediation social outcomes. Postremediation political activism may shift to focus on property rights, risk mitigation techniques, institutional controls, and land use (Little 2012, 2014; McCaffrey 2018), but continuities in struggle remain.

Attention to the multifaceted connections between bodies and toxicity before and during cleanups (Benadusi 2018; Little 2012, 2019; Nading 2020; Povinelli 2017; Shapiro 2015; Tironi 2018; Tironi and Rodríguez-Giralt 2017) brings attention to continuities in suffering after remediation. The slowness of contamination from petrochemical plants, Benadusi (2018) argues, has increased the permeability of bodies to toxicity—not in a toxicological sense of magnifying exposure pathways; rather, in the sense of normalizing pollution as part of one's environment and body. The causes of suffering may be as much from historic, institutional harms as from actual material substances, as reflected in indigenous communities' suffering from contaminated sites (Hoover 2017; Tsosie 2015). Additionally, suffering does not necessarily go away when cleanups begin (Petryna 2002). Remedial or removal actions can contribute to new forms of pain. For example, risk mitigation techniques at the IBM-Endicott Superfund site in New York created their own "emotional ecology" for affected residents, who had to live with vapor intrusion control technologies in their homes (Little 2012).

Continuities in toxicity, suffering, and struggles helps explain why social actors and institutions differ in their interpretations of how clean is clean and when a cleanup is over. Deletion of a site from the National Priorities List or redevelopment of a brownfield can be cause for celebration. If there are ongoing sources of pollution, suffering from toxicity, and unhealthy chemical-social relationships, though, it is also a reminder that more needs to be done. Signs of success through the achievement of reuse, reoccupation, and redevelopment may mask continuities in toxicity and political struggles. For example, residential areas have sprouted up near the Rocky Flats Wildlife Refuge, formerly the Rocky Flats Industrial Park Superfund site, in Colorado. While this development is one indicator of success, former residents continue to express concerns over unresolved health issues (Alexis-Martin and Malin 2017; Iversen 2013). 


\section{Postremediation Social Worlds}

Another theme within the literature is how environmental cleanups shape social worlds-that is, how outcomes affect relationships among people, history, and nature. As a result, we find that postremediation landscapes have new types of social worlds. Researchers have begun to describe this type of worldmaking and relationality in a number of ways such as "chemo-sociality" (Shapiro and Kirksey 2017) and "toxic worldmaking" (Nading 2020). Michelle Murphy (2017) uses the notion of "afterlife" to unpack how our lives, bodies and relationships are impacted by our exposure to chemicals. These examples provide useful frameworks for understanding the complex, often insidious ways in which pollution/toxicity is reshaping culture through the creation of new social worlds and may continue to do so after remediation.

The literature we reviewed highlights the specific ways in which remediation and postremediation create new social worlds. Cleanups are creating new landscapes of institutional and technocratic control (Fletcher 2002; Krupar 2011; Little 2014; Shriver et al. 2008). This is because the completion of the final cleanup stages (e.g., construction complete, deletion, redevelopment) does not necessarily mean the end of contamination or the end of environmental management and monitoring. At the Hanford nuclear site in Washington, dealing with radioactive tumbleweeds that did not heed site boundaries required significant efforts and resources (Masco 2004). Some Superfund remedies involve institutional controls, or administrative or legal restrictions on access and use, to limit human exposure to residual contamination. For example, there may be limits set on fish consumption from rivers near a site that continues postremediation.

Implementation of institutional controls as well as general postremediation management requires ongoing social relationships and trust (Kiessling et al. 2021), leading to new social worlds of engagement and care. Care of environments, humans, and animals affected by pollution may need to continue after remediation (Beckett and Keeling 2019; Shriver et al. 2008; Tironi 2018; Tironi and Rodríguez-Giralt 2017; Waterton et al. 2015). Care of environments and bodies is reflective and constitutive of political relationships. It may originate from the ground up, in the tinkering and maintenance practices of waste workers (Ureta 2016) or as a form of "intimate activism" and "hypo-interventions" in domestic spaces of contaminated communities (Tironi 2018; Tironi and Rodríguez-Giralt 2017). Conversely, it can operate top-down, shifting the burden for monitoring and managing environmental harms from corporations to those most affected (Nading 2020; Shapiro 2015). Postremediation care of contaminated bodies and environments involves multifaceted relationships, governance, and knowledge over a potentially expansive spatial and temporal scale (Beckett and Keeling 2019; Waterton et al. 2015).

Environmental cleanups are also shaping social worlds through the way in which they engage history. Our article highlights how postremediated sites may memorialize histories of industry and contamination (Bluestone 2007; Cram 2016; Havlick 2016). The sites become educational, acknowledging past mistakes and honoring the sacrifices that past workers at the site may have made. This points to opportunities where communities may heal from painful entanglements with pollution and achieve restorative justice (Beckett and Keeling 2019; Hoover 2017; Tsosie 2015). It also demonstrates the duality that postremediation landscapes may represent, "embody[ing] ruin and redemption" (Cram 2016: 91). This is particularly exemplified in cases where former military sites have become wildlife refuges, such as Rocky Flats and Vieques (Krupar 2011; McCaffrey 2018). However, some postremediation transformations may obscure or erase certain legacies, particularly histories of violence, exploitation, and racism (Blanton 2011). This may lead to communities' losing important knowledge about what happened at those sites, what their own histories are, or what dangers may still lurk (Bluestone 2007; Coates 
2016; Dillon 2014). It also raises the issue of whose history is being represented and whose is not (Davis et al. 2007). Such erasures are important to uncover because otherwise they may perpetuate inequalities and trauma.

Another way that environmental cleanups create new social worlds is through changing relationships with nature. Remediation reduces radiological or chemical contamination in one place; meanwhile, background levels of radiation have increased through the Anthropocene (Masco 2004). The "inability to enforce the distinction between wilderness and wasteland" (Masco 2004: 533) becomes starker when examining the entanglements of postremediated and nonremediated landscapes, or pre- and postremediated landscapes. Consequently, postremediation landscapes that become places of nature conservation force us to reconsider common notions of nature as nontoxic (Alexis-Martin and Malin 2017; McCaffrey 2018). These insights lead us to question traditional frameworks of environmental management based on the "politics of material purity" (Liboiron et al. 2018: 332; Shapiro et al. 2020). As a result, we are left with tensions over deciding what should be restored-whose nature and for whom (Quivik 2016).

\section{Connecting Social Science with Cleanup Management and Outcomes}

\section{Implications for the Cleanup Process}

Our discussion in the sections above highlights ways in which social science research has begun to engage with environmental cleanup outcomes. However, we have also underscored significant disconnects between the critical anthropological, STS, geographical, and sociological research analyzed here and outcome-oriented work. As such, we turn to discuss opportunities for greater integration of social science considerations in environmental cleanups and evaluations. The literature reviewed here identifies ways that social science insights might inform cleanup decisions. Starting with preremediation planning, Valerie Cappuyns (2016) suggests that environmental managers should not only consider human health and safety, but also neighborhood and locality, ethics and equality, community involvement, and uncertainty and evidence. Environmental managers could prioritize community healing and restorative justice as a cleanup goal, helping communities to recover from the traumas and injustices intertwined with contamination (Beckett and Keeling 2019; Tsosie 2015). Fostering new social and institutional relationships and building trust among social actors during cleanups is part of achieving such objectives (Kiessling et al. 2021; Lange and McNeil 2004; Metcalf et al. 2015; Ulibarri et al. 2020). Postremediation management could form new collaborations for the ongoing care of damaged environments and bodies (Tironi and Rodríguez-Giralt 2017; Ureta 2016; Waterton et al. 2015). Attention could also go toward the memorialization and preservation of the cultural histories at remediated sites (Beckett and Keeling 2019; Coates 2016; Davis et al. 2007).

Additionally, cleanup processes can make space for mutual learning and exploration, a "knowledge collective" that could feed into decision-making (Waterton 2017). This would give power to different types of knowledge and recognize the multiple lived realities at contaminated sites (Allen 2020; Choy 2005; Clapp et al. 2016; Shriver et al. 2008). For example, the Rocky Flats Superfund site used the co-production of knowledge by establishing community panels empowered to establish soil action levels alongside scientists, which the researchers assert produced levels that were more technically defensible and publicly acceptable (Till and Meyer 2001). Matthias Gross's (2016) concept of "nonknowledge" also provides a framework that environmental managers could use to constructively work through gaps in knowledge that are prevalent in cleanup processes. 


\section{New Directions for Measuring Outcomes}

As STS literature demonstrates, the evaluation of cleanup outcomes might incorporate more socially oriented measures as well as new ways of measuring that are more inclusive of distinct ways of knowing and that involve a greater variety of social actors (Allen 2020; Delbourne and Galusky 2011; Frickel et al. 2009; Hoover 2020; Morello-Frosch et al. 2011; Nading 2020). Lenora Bohren (2005) explicitly calls for anthropologists to become more involved with environmental evaluation projects and to bring with them holistic perspectives and the use of qualitative and quantitative techniques. Ethnography, in particular, can create space for deliberation and so "loop, turning ethnographic findings back into the system" (Fortun 2012: 456). Applying place-based, cultural perspectives to how cleanup outcomes are understood and evaluated might bring more attention to systems of power, equity, race, and geographic diversity in environmental management. Consideration of postremediation social worlds also helps us to bear witness to the cultural changes that cleanups create. Such considerations may act as a way-finder for assessing whether cleanups remediate social relationships (Beckett and Keeling 2019) or chemical-social relationships (Shapiro and Kirksey 2017); whether they reproduce geographies of injustice (Dillon 2014) or restore justice (Tsosie 2015).

A more holistic framework for evaluating cleanup outcomes, one that embraces intersectionality and interdisciplinarity, is not merely an exercise in evaluation, however. Paraphrasing Donella Meadows (1998), what counts gets measured and what gets measured counts. Given the circular temporalities between future sociotechnical imaginaries and site decisions, it is possible that better delineating the contours of postremediation social worlds could affect changes in the cleanup processes needed to get there.

In addition to ideas for a holistic framework, a number of researchers have suggested different social outcomes that could be tracked. For example, jobs created or increases in tax revenue can show impacts on community economies. Changes to quality of life can be tracked by amount of green space created, reduction in fear or anxiety, or increase in affordable housing (Bacot and O’Dell 2006; Cappuyns 2016; Lange and McNeil 2004; Tonin 2014; Tuler et al. 2007; Wedding and Crawford-Brown 2007). Cleanup volunteerism rates and related demographics of cleanup laborers could shed more light on how cleanups affect the workforce and labor practices (Sharpe et al. 2019). Usage and user perceptions of postremediated sites could be collected to understand how cleanups may affect place-making (Heatherington et al. 2019; Newman 2011). Measures could gather the experiences and emotions of living with toxicity, including continuities in suffering. They could track ongoing management and care of bodies, sites, and environments. They could address community engagement, trust, and risk perceptions in the context of ongoing political struggles (i.e., racial equality, environmental justice, tribal sovereignty, and urban development).

Other researchers have suggested innovative techniques to setting outcomes and completing evaluations. For example, the incorporation of citizen science and popular epidemiology are ways to overcome the politics of expertise (Hoover 2020; Morello-Frosch et al. 2011; Polleri 2019). Digital activism could be used as a site-monitoring method (Delbourne and Galusky 2011). Defining cleanup endpoints and the levels needed to meet those endpoints could be done in a local, participatory manner to select endpoints that are culturally relevant (Johnson and Ranco 2011).

\section{Areas for New Inquiry}

Our review of current research on environmental cleanup outcomes identifies opportunities for new areas of inquiry. We have highlighted many ideas for holistic frameworks for analyzing societal outcomes and measures, and pointed to researchers who have contributed to this 
line of work. Social scientists could continue to flesh these frameworks out, adding in the lessons learned from this article. They could also assess how different social actors conceptualize whether or not cleanups are a success.

Another area of inquiry is investigating how existing cleanup measures and narratives are created and used by various social actors. For example, the EPA produces written communications about Superfund and brownfield success stories, as well as annual reports of performance metrics (e.g., EPA 2020). How do other social actors involved with cleanups find, interpret, and use these materials? In a similar vein, we have highlighted academic articles that propose new or modified evaluation techniques such as lifecycle assessments and citizen science. Is there uptake of these techniques by environmental and health agencies responsible for cleanups? These are questions that warrant more investigation.

More research could also be done concerning the social worlds of postremediation landscapes themselves as such landscapes become more common and unfold into potentially new "post-postremediation stages." For example, where and how are the potentially responsible parties (the polluters) in postremediation landscapes (Liboiron et al. 2018; Nading 2020)? How is ongoing care of damaged bodies, environments, and relationships progressing (Shriver et al. 2008; Tironi and Rodríguez-Giralt 2017; Waterton 2017)? Building from Anna Tsing's work where she asks us to find "possibilities of coexistence with environmental disturbance" (2017: 4), what opportunities do postremediated sites offer that have yet to be explored? How can we embrace this disturbance and degradation, and breathe new life into sites? How do socioenvironmental dynamics affect the patchiness of postremediation landscapes? As more sites move through cleanup processes, these topics will be increasingly important to address, particularly as we expand our understanding of cleanup to include the pre and post phases.

Our article also opens the door for thinking about implications for broader social science theories. For example, we draw on social science works on pollution/toxicity to critically analyze the technoscience of how cleanup levels and outcomes are measured. How does this analysis of cleanup measures help us deepen our understanding of the broader literature on environmental measurement and monitoring? Does it point to new things to study? Does it make us see other literature in a new light?

\section{Conclusion}

In this article, we review current themes on conceptualizing and evaluating environmental cleanup outcomes. By focusing on the postremediation stage of cleanups, our review broadens our understanding of the sociopolitical life of contaminated sites. Our discussion brings multiple social science disciplines and perspectives into conversation with each other in a novel way. We analyze the technoscientific practices of how cleanup levels and outcomes are measured. The technoscientific practices of evaluating outcomes are grounded in quantitative approaches to measuring the environment and society, and rely on a politics of expertise. Current measures of outcomes found in the literature can tell better stories about some cleanup situations and outcomes than they can about others. Economic analyses of changes in housing price continue to be the main way of evaluating societal outcomes. There is a dearth of outcome measures that capture postremediation social worlds. Although this search found proposed frameworks and measures for assessing societal outcomes more holistically, few have been tested or applied in practice.

By bringing in adjacent literature on pollution/toxicity, we reveal the circular temporalities of cleanups. Determining and achieving cleanup levels and outcomes is not a linear trajectory that runs clearly from start to finish. Instead, the process can feed back onto itself. We highlight 
the continuities in political struggle and continuities in suffering that make the determination of when a cleanup is over less clear-cut. Suffering may not go away with the beginning or end of remedial actions. Signs of cleanup success may mask deep-rooted traumas along with longstanding and ongoing social struggles. We also highlight the multifaceted ways that cleanup processes and outcomes shape social worlds, drawing attention to new relationships among people, history, and nature. We conclude with a discussion of opportunities for better connecting social science to environmental cleanup outcomes and measures. We highlight techniques for building social considerations into cleanup processes as well as new ideas for outcomes measures that better capture the complexities of postremediation social worlds. We also provide areas for future inquiry that may help us incorporate multiple ways of knowing to better refine our understanding of postremediation social worlds and landscapes. Overall, our discussion provides a roadmap for where we have been, and points to where the social science research on environmental cleanup outcomes and postremediation social worlds can go in the future.

\section{ACKNOWLEDGMENTS}

We would like to thank Karen Sullivan for providing materials on brownfields, as well as Kate Mulvaney, Emily Eisenhauer, and the journal editors and anonymous reviewers for providing constructive feedback. Thank you to Jenny Buckley for contributing to early pieces of this research that provided the foundation for this project. We also greatly appreciate the funding, support, and guidance provided by the EPA Homeland Security Research Program.

Disclaimer: This document has been reviewed in accordance with EPA policy and approved for publication. The views expressed in this article are those of the authors, and do not necessarily represent the views or the policies of the EPA.

BRITTANY KIESSLING is a Cultural Anthropologist with expertise in disaster studies and community resilience research. She specializes in applying cultural perspectives to address environmental problems. She is currently a Federal Postdoc in the Center for Environmental Solutions and Emergency Response (CESER) in the EPA's Office of Research and Development. Email: kiessling.brittany@epa.gov

UEELY MAXWELL works as a General Anthropologist in the Center for Environmental Solutions and Emergency Response (CESER) in the EPA's Office of Research and Development. Her current research centers on the intersection of disasters, resilience, and the environment. She also analyzes the interdisciplinary integration of social and biophysical sciences in environmental and global change research. Email: maxwell.keely@epa.gov

\section{REFERENCES}

Ahmann, Chloe. 2018. “'It's Exhausting to Create an Event out of Nothing': Slow Violence and the Manipulation of Time." Cultural Anthropology 33 (1): 142-171. doi:10.14506/ca33.1.06.

Ahmann, Chloe. 2019. "Waste to Energy: Garbage Prospects and Subjunctive Politics in Late-Industrial Baltimore." American Ethnologist 46 (3): 328-342. doi:10.1111/amet.12792. 
Alexis-Martin, Becky, and Stephanie Malin. 2017. "An Unnatural History of Rocky Flats National Wildlife Refuge, Colorado." Arcadia: Explorations in Environmental History 25: 1-6. doi:10.5282/rcc/7975.

Allen, Barbara L. 2007. "Environmental Justice, Local Knowledge, and After-Disaster Planning in New Orleans." Technology in Society 29 (2): 153-159. doi:10.1016/j.techsoc.2007.01.003.

Allen, Barbara L. 2020. "Making Effective Participatory Environmental Health Science through Collaborative Data Analysis." In Toxic Truths: Environmental Justice and Citizen Science in a Global Age, ed. Thom Davis and Alice Mah, 59-81. Manchester: Manchester University Press.

Ando, Ryoko. 2018. “Trust: What Connects Science to Daily Life." Health Physics 115 (5): 581-589. doi:10.1097/hp.0000000000000945.

Bacot, Hunter, and Cindy O’Dell. 2006. "Establishing Indicators to Evaluate Brownfield Redevelopment." Economic Development Quarterly 20 (2): 142-161. doi:10.1177/0891242405285749.

Beckett, Caitlynn, and Arn Keeling. 2019. "Rethinking Remediation: Mine Reclamation, Environmental Justice, and Relations of Care." Local Environment 24 (3): 216-230. doi:10.1080/13549839.2018.155 7127.

Benadusi, Mara. 2018. "Oil in Sicily: Petrocapitalist Imaginaries in the Shadow of Old Smokestacks." Economic Anthropology 5 (1): 45-58. doi:10.1002/sea2.12101.

Blanton, Ryan. 2011. "Chronotopic Landscapes of Environmental Racism." Journal of Linguistic Anthropology 21 (S1): E76-E93. doi:10.1111/j.1548-1395.2011.01098.x.

Bluestone, Daniel 2007. "Toxic Sites as Places of Culture and Memory: Adaptive Management for Citizenship." In Reclaiming the Land: Rethinking Superfund Institutions, Methods and Practices, ed. Gregg P. Macey and Jonathan Z. Cannon, 245-266. New York: Springer.

Bohren, Lenora. 2005. "Evaluation of Environmental Issues." NAPA Bulletin 24 (1): 49-56. doi:10.1525/ napa.2005.24.1.049.

Bond, David. 2013. "Governing Disaster: The Political Life of the Environment during the BP Oil Spill." Cultural Anthropology 28 (4): 694-715. doi:10.1111/cuan.12033.

Burger, Joanna. 2019. "Costs and Benefits of Delaying Remediation on Ecological Resources at Contaminated Sites." EcoHealth 16 (3): 454-475. doi:10.1007/s10393-019-01437-z.

Burger, Joanna, M. Gochfeld, D. S. Kosson, K. G. Brown, L. S. Bliss, A. Bunn, . . , and J. A. Salisbury. 2019. "The Costs of Delaying Remediation on Human, Ecological, and Eco-Cultural Resources: Considerations for the Department of Energy: A Methodological Framework." Science of the Total Environment 649: 1054-1064. doi:10.1016/j.scitotenv.2018.08.232.

Cappuyns, Valerie. 2016. "Inclusion of Social Indicators in Decision Support Tools for the Selection of Sustainable Site Remediation Options." Journal of Environmental Management 184 (Pt 1): 45-56. doi:10.1016/j.jenvman.2016.07.035.

Chattopadhyay, Sudip, John B. Braden, and Arianto Patunru. 2005. "Benefits of Hazardous Waste Cleanup: New Evidence from Survey- and Market-Based Property Value Approaches." Contemporary Economic Policy 23 (3): 357-375. doi:10.1093/cep/byi027.

Checker, Melissa. 2007. “"But I know It’s True”: Environmental Risk Assessment, Justice, and Anthropology." Human Organization 66 (2): 112-124. http://www.jstor.org/stable/44127105.

Checker, Melissa. 2011. "Wiped out by the 'Greenwave': Environmental Gentrification and the Paradoxical Politics of Urban Sustainability." City and Society 23 (2): 210-229. doi:10.1111/j.1548744X.2011.01063.x.

Choy, Timothy K. 2005. "Articulated Knowledges: Environmental Forms after Universality's Demise." American Anthropologist 107 (1): 5-18. doi:10.1525/aa.2005.107.1.005.

Clapp, Justin T., Jody A. Roberts, Britt Dahlberg, Lee Sullivan Berry, Lisa M. Jacobs, Edward A. Emmett, and Frances K. Barg. 2016. "Realities of Environmental Toxicity and Their Ramifications for Community Engagement." Social Science \& Medicine 170: 143-151. doi:10.1016/j.socscimed.2016.10.019.

Coates, Peter. 2016. “'Get Lost in the Footnotes of History': The Restorative Afterlife of Rocky Flats." In Restoring Layered Landscapes: History, Ecology, and Culture, edited by Marion Hourdequin and David G. Havlick, 133-159. New York: Oxford University Press.

Cram, Shannon. 2016. "Wild and Scenic Wasteland: Conservation Politics in the Nuclear Wilderness." Environmental Humanities 7 (1): 89-105. doi:10.1215/22011919-3616344. 
Crutzen, Paul J. 2006. “The 'Anthropocene.” In Earth System Science in the Anthropocene, ed. Eckart Ehlers and Thomas Krafft, 13-18. Berlin: Springer.

Cruz, Shannon M. 2019. “Themes across New Directions in Community Engagement.” International Journal of Environmental Research and Public Health 16 (19): 3724. doi:10.3390/ijerph16193724.

Davis, Jeffrey Sasha, Jessica S. Hayes-Conroy, and Victoria M. Jones. 2007. "Military Pollution and Natural Purity: Seeing Nature and Knowing Contamination in Vieques, Puerto Rico." Geojournal 69: 165-179. doi:10.1007/s10708-007-9095-7.

Delbourne, Jason, and Wayne Galusky. 2011. “Toxic Transformations: Constructing Online Audiences for Environmental Justice." In Technoscience and Environmental Justice: Expert Cultures in a Grassroots Movement, ed. Gwen Ottinger and Benjamin Cohen, 63-92. Cambridge: MIT Press.

Dillon, Lindsey. 2014. "Race, Waste, and Space: Brownfield Redevelopment and Environmental Justice at the Hunters Point Shipyard." Antipode 46 (5): 1205-1211. doi:10.1111/anti.12009.

EPA (US Environmental Protection Agency). 2020. Superfund FY2019: Annual Accomplishments Report. Washington, DC: US Environmental Protection Agency.

Fejes, Jonas, A. Martinsson, and E. Lindblom. 2008. "How Clean Is Clean? Development of Monitoring Methods to Determine Environmental and Socially Acceptable End-Points of Clean-Up." In Oil Spill Response: A Global Perspective, ed. Walter F. Davidson, Kenneth Lee, and Andrew Cogswell, 199-200. Dordrecht: Springer Netherlands.

Fletcher, Thomas. 2002. "Neighbourhood Change at Love Canal: Contamination, Evacuation and Resettlement." Land Use Policy 19: 311-323. doi:10.1016/S0264-8377(02)00045-5.

Fortun, Kim. 2012. “Ethnography in Late Industrialism." Cultural Anthropology 27 (3): 446-464. doi:10.1111/j.1548-1360.2012.01153.x.

Frickel, Scott. 2012. "Missing New Orleans: Tracking Knowledge and Ignorance through an Urban Hazardscape." In Histories of the Dustheap: Waste, Material Cultures, Social Justice, ed. Stephanie Foote and Elizabeth Mazzolini, 97-117. Cambridge, MA: MIT Press.

Frickel, Scott, Richard Campanella, and M. Bess Vincent. 2009. "Mapping Knowledge Investments in the Aftermath of Hurricane Katrina: A New Approach for Assessing Regulatory Agency Responses to Environmental Disaster." Environmental Science and Policy 12 (2): 119-133. doi:10.1016/j.envsci .2008.11.006.

Frickel, Scott, and M. Bess Vincent. 2007. "Hurricane Katrina, Contamination, and the Unintended Organization of Ignorance.” Technology in Society 29 (2): 181-188. doi:10.1016/j.techsoc.2007 .01 .007 .

Gamper-Rabindran, Shanti, and Christopher Timmins. 2011. "Hazardous Waste Cleanup, Neighborhood Gentrification, and Environmental Justice: Evidence from Restricted Access Census Block Data." American Economic Review 101 (3): 620-624. doi:10.1257/aer.101.3.620.

Gamper-Rabindran, Shanti, and Christopher Timmins. 2013. "Does Cleanup of Hazardous Waste Sites Raise Housing Values? Evidence of Spatially Localized Benefits." Journal of Environmental Economics and Management 65 (3): 345-360. doi:10.1016/j.jeem.2012.12.001.

Gephart, Roy E. 2003. Hanford: a Conversation about Nuclear Waste and Cleanup. Columbus, Ohio: Battelle Press.

Grant, Maria J., and Andrew Booth. 2009. "A Typology of Reviews: An Analysis of 14 Review Types and Associated Methodologies." Health Information \& Libraries Journal 26 (2): 91-108. doi:10.1111/ j.1471-1842.2009.00848.x.

Greenstone, Michael, and Justin Gallagher. 2008. "Does Hazardous Waste Matter? Evidence from the Housing Market and the Superfund Program.” Quarterly Journal of Economics 123 (3): 951-1003. doi:10.1162/qjec.2008.123.3.951.

Gross, Matthias. 2016. "Layered Industrial Sites: Experimental Landscapes and the Virtues of Ignorance." In Restoring Layered Landscapes: History, Ecology, and Culture, ed. Marion Hourdequin and David G. Havlick, 73-91. New York: Oxford University Press.

Guignet, Dennis, Robin Jenkins, Matthew Ranson, and Patrick Walsh. 2018. “Contamination and Incomplete Information: Bounding Implicit Prices Using High-Profile Leaks.” Journal of Environmental Economics and Management 88: 259-282. doi:10.1016/j.jeem.2017.12.003. 
Guignet, Dennis, and Adan Martinez-Cruz. 2018. “The Impacts of Underground Petroleum Releases on a Homeowner's Decision to Sell: A Difference-in-Differences Approach.” Regional Science and Urban Economics 69: 11-24. doi:10.1016/j.regsciurbeco.2017.12.006.

Hart, Chris. 1998. Doing a Literature Review: Releasing the Social Science Research Imagination. London: SAGE Publications.

Havlick, David G. 2016. "Restoration, History, and Values at Transitioning Military Sites in the United States." In Restoring Layered Landscapes: History, Ecology, and Culture, ed. Marion Hourdequin and David G. Havlick, 160-182. New York: Oxford University Press.

Heatherington, Catherine, Anna Jorgensen, and Stephen Walker. 2019. "Understanding Landscape Change in a Former Brownfield Site." Landscape Research 44 (1): 19-34. doi:10.1080/01426397 .2017.1374359.

Hird, Myra J. 2017. "Waste, Environmental Politics and Dis/Engaged Publics." Theory, Culture, and Society 34 (2-3): 187-209. doi:10.1177/0263276414565717.

Hoffman, Andrew J. 1995. "An Uneasy Rebirth at Love Canal." Environment 37 (2): 4-31. doi:10.1080/ 00139157.1995.9929215.

Hoover, Elizabeth. 2017. The River Is In Us: Fighting Toxins in a Mohawk Community. Minneapolis: University of Minnesota Press.

Hoover, Elizabeth. 2020. "Whose Citizenship in 'Citizen Science?' Tribal Identity, Civic Dislocation, and Environmental Health Research.” In Toxic Truths: Environmental Justice and Citizen Science in a Global Age, ed. Thom Davis and Alice Mah, 243-266. Manchester: Manchester University Press.

Iversen, Kristen. 2013. Full Body Burden: Growing Up in the Shadow of Rocky Flats. New York: Broadway Books.

Jasanoff, Sheila. 2015. “Future Imperfect: Science, Technology, and the Imaginations of Modernity.” In Dreamscapes of Modernity: Sociotechnical Imaginaries and the Fabrication of Power, ed. Sheila Jasanoff and Sang-Hyun Kim, 1-33. Chicago: University of Chicago Press.

Johnson, Jaclyn, and Darren Ranco. 2011. "Risk Assessment and Native Americans at the Cultural Crossroads: Making Better Science or Redefining Health?” In Technoscience and Environmental Justice: Expert Cultures in a Grassroots Movement, ed. Gwen Ottinger and Benjamin Cohen, 179-200. Cambridge, MA: MIT Press.

Jorgensen, Timothy. 2016. “The New "Normal”: Stakeholders and Radiation Protection Limits in a Post-9/11 World." Journal of Health Physics 111 (2): 227-231. https://doi.org/10.1097/HP.00000 0000000457.

Keeling, Arn, and John Sandlos. 2017. "Ghost Towns and Zombie Mines: The Historical Dimensions of Mine Abandonment, Reclamation and Redevelopment in the Canadian North." In Ice Blink: Navigating Northern Environmental History, ed. Stephen Bocking and Brad Martin, 377-420. Calgary: University of Calgary Press.

Ketkar, Kusum. 1992. "Hazardous Waste Sites and Property Values in the State of New Jersey." Applied Economics 24 (6): 647-659. doi:10.1080/00036849200000033.

Kiel, Katherine. 1995. "Measuring the Impact of the Discovery and Cleaning of Identified Hazardous Waste Sites on House Values." Land Economics 71 (4): 428-435. doi:10.2307/3146708.

Kiessling, Brittany, Keely Maxwell, and Jenifer A. Buckley. 2021. "The Sedimented Social Histories of Environmental Cleanups: An Ethnography of Social and Institutional Dynamics." Journal of Environmental Management 278 (2): 111530. doi:10.1016/j.jenvman.2020.111530.

Krupar, Shiloh R. 2011. "Alien Still Life: Distilling the Toxic Logics of the Rocky Flats National Wildlife Refuge." Environment and Planning D: Society and Space 29 (2): 268-290. doi:10.1068/d12809.

Lanari, Elisa. 2019. "Envisioning a New City Center: Time, Displacement, and Atlanta's Suburban Futures." City and Society 31 (3): 365-391. doi:10.1111/ciso.12224.

Lang, Corey, and Patrick Cavanagh. 2018. "Incomplete Information and Adverse Impacts of Environmental Cleanup." Land Economics 94 (3): 386-404. doi:10.3368/le.94.3.386.

Lange, Deborah A., and Sue McNeil. 2004. "Clean It and They Will Come? Defining Successful Brownfield Development." Journal of Urban Planning and Development-Asce 130 (2): 101-108. doi:10.1061/(ASCE)0733-9488(2004)130:2(101). 
Lehigh, Gabrielle R., E. Christian Wells, and Diana Diaz. 2020. "Evidence-Informed Strategies for Promoting Equitability in Brownfields Redevelopment." Journal of Environmental Management 261: 110150. doi:10.1016/j.jenvman.2020.110150.

Liboiron, Max, Manuel Tironi, and Nerea Calvillo. 2018. “Toxic Politics: Acting in a Permanently Polluted World." Social Studies of Science 48 (3): 331-349. doi:10.1177/0306312718783087.

Little, Peter C. 2012. "Another Angle on Pollution Experience: Toward an Anthropology of the Emotional Ecology of Risk Mitigation." Ethos 40 (4): 431-452. doi:10.1111/j.1548-1352.2012.01269.x.

Little, Peter C. 2013. "Envisioning the Political Ecology of Mitigation in a Microelectronic Disaster Setting." Journal of Political Ecology 20 (1): 2017-237. doi:10.2458/v20i1.21765.

Little, Peter C. 2014. Toxic Town: IBM, Pollution and Industrial Risks. New York: NYU Press.

Little, Peter C. 2019. "Bodies, Toxins, and E-waste Labour Interventions in Ghana: Toward a Toxic Postcolonial Corporality?” Aibr-Revista De Antropologia Iberoamericana 14 (1): 51-71. doi:10.11156/ aibr.140104.

Maantay, Juliana A., and Andrew R. Maroko. 2018. "Brownfields to Greenfields: Environmental Justice versus Environmental Gentrification.” International Journal of Environmental Research and Public Health 15 (10). doi:10.3390/ijerph15102233.

MacFarlane, Key. 2019. “Time, Waste, and the City: The Rise of the Environmental Industry." Antipode 51 (1): 225-247. doi:10.1111/anti.12427.

Masco, Joseph. 2004. "Mutant Ecologies: Radioactive Life in Post-Cold War New Mexico." Cultural Anthropology 19 (4): 517-550. doi:10.1525/can.2004.19.4.517.

Mastromonaco, Ralph, and Peter Maniloff. 2018. "An Examination of Geographic Heterogeneity in Price Effects of Superfund Site Remediation.” Economics Letters 171: 23-28. doi:10.1016/j.econlet .2018.06.026.

Maxwell, Keely, Brittany Kiessling, and Jenifer A. Buckley. 2018. "How Clean Is Clean: A Review of the Social Science of Environmental Cleanups." Environmental Research Letters 13 (8): 083002. doi:10 $.1088 / 1748-9326 / \mathrm{aad} 74 \mathrm{~b}$.

McCaffrey, Katherine. 2018. "Environmental Remediation and Its Discontents: The Contested Cleanup of Vieques, Puerto Rico." Journal of Political Ecology 25: 80-103. doi:10.2458/v25i1.22631.

Meadows, Donella. 1998. Indicators and Information Systems for Sustainable Development. Hartland, VT: The Sustainability Institute.

Messer, Kent D., William D. Schulze, Katherine F. Hackett, Trudy A. Cameron, and Gary H. McClelland. 2006. "Can Stigma Explain Large Property Value Losses? The Psychology and Economics of Superfund." Environmental and Resource Economics 33 (3): 299-324. doi:10.1007/s10640-005-3609-x.

Metcalf, Elizabeth Covelli, Jakki J. Mohr, Laurie Yung, Peter Metcalf, and David Craig. 2015. “The Role of Trust in Restoration Success: Public Engagement and Temporal and Spatial Scale in a Complex Social-Ecological System." Restoration Ecology 23 (3): 315-324. doi:10.1111/rec.12188.

Morello-Frosch, Rachel, Phil Brown, Julia Green Brody, Rebecca Gasior Altman, Ruthanne A. Rudel, Ami Zota, and Carla Pérez. 2011. "Experts, Ethics, and Environmental Justice: Communicating Results from Personal Exposure Science." In Technoscience and Environmental Justice: Expert Cultures in a Grassroots Movement, ed. Gwen Ottinger and Benjamin Cohen, 93-118. Cambridge, MA: MIT Press.

Murphy, Michelle. 2017. “Alterlife and Decolonial Chemical Relations." Cultural Anthropology 32 (4): 494-503. doi:10.14506/ca32.4.02.

Nading, Alex M. 2020. “Living in a Toxic World.” Annual Review of Anthropology 49 (1): 209-224. doi:10.1146/annurev-anthro-010220-074557.

Newman, Andrew. 2011. "Contested Ecologies: Environmental Activism and Urban Space in Immigrant Paris." City and Society 23 (2): 192-209. doi:10.1111/j.1548-744X.2011.01062.x.

Petryna, Adriana 2002. Life Exposed: Biological Citizens after Chernobyl. Princeton, NJ: Princeton University Press.

Polleri, Maxime. 2019. "Conflictual Collaboration: Citizen Science and the Governance of Radioactive Contamination after the Fukushima Nuclear Disaster." American Ethnologist 46 (2): 214-226. doi:10.1111/amet.12763. 
Povinelli, Elizabeth A. 2017. “Fires, Fogs, Winds.” Cultural Anthropology 32 (4): 504-513. doi:10.14506/ ca32.4.03.

Quivik, Frederic L. 2016. "Renaturalization and Industrial Heritage in America’s Largest Superfund Site: The Case of Warm Springs Ponds in Montana’s Clark Fork Superfund Site." In Restoring Layered Landscapes: History, Ecology, and Culture, ed. Marion Hourdequin and David G. Havlick, 202-221. New York: Oxford University Press.

Roberts, Elizabeth F. S. 2017. "What Gets Inside: Violent Entanglements and Toxic Boundaries in Mexico City." Cultural Anthropology 32 (4): 592-619. doi:10.14506/ca32.4.07.

Savchenko, Olesya M., and John B. Braden. 2019. "Do Public Benefits of Voluntary Cleanup Programs Justify Their Public Costs? Evidence from New York.” Land Economics 95 (3): 369-390. doi:10.3368/ le.95.3.369.

Shapiro, Nicholas. 2015. "Attuning to the Chemosphere: Domestic Formaldehyde, Bodily Reasoning, and the Chemical Sublime." Cultural Anthropology 30 (3): 368-393. doi:10.14506/ca30.3.02.

Shapiro, Nicholas, and Eben Kirksey. 2017. "Chemo-Ethnography: An Introduction." Cultural Anthropology 32 (4): 481-493. doi:10.14506/ca32.4.01.

Shapiro, Nicholas, Nassir Zakariya, and Jody A. Roberts. 2020. "Beyond the Data Treadmill: Environmental Enumeration, Justice, and Apprehension." In Toxic Truths: Environmental Justice and Citizen Science in a Global Age, ed. Thom Davis and Alice Mah, 301-325. Manchester: Manchester University Press.

Sharpe, J. Danielle, John A. Kaufman, Zachary E. Goldman, Amy Wolkin, and Matthew O. Gribble. 2019. "Determinants of Oil-Spill Cleanup Participation Following the Deepwater Horizon Oil Spill." Environmental Research 170: 472-480. doi:10.1016/j.envres.2019.01.009.

Shriver, Thomas E., Sherry Cable, and Dennis Kennedy. 2008. "Mining for Conflict and Staking Claims: Contested Illness at the Tar Creek Superfund Site." Sociological Inquiry 78 (4): 558-579. doi:10.1111/ j.1475-682X.2008.00258.x.

Thomas, James, and Angela Harden. 2008. "Methods for the Thematic Synthesis of Qualitative Research in Systematic Reviews." BMC Medical Research Methodology 8 (1): 45. doi:10.1186/1471-2288-8-45.

Till, John E., and Kathleen R. Meyer. 2001. "Public Involvement in Science and Decision-Making." Health Physics 80 (4): 370-378. doi:10.1097/00004032-200104000-00014.

Tironi, Manuel. 2018. "Hypo-Interventions: Intimate Activism in Toxic Environments." Social Studies of Science 48 (3): 438-455. doi:10.1177/0306312718784779.

Tironi, Manuel, and Israel Rodríguez-Giralt. 2017. "Healing, Knowing, Enduring: Care and Politics in Damaged Worlds.” Sociological Review Monographs 65 (Supp 2): 89-109. doi:10.1177/008117691 7712874.

Tonin, Stefania. 2014. "Assessing the Impact of the Remedial Actions Taken at a Contaminated Italian Site: An Ex-Post Valuation Analysis." Reviews in Environmental Science and Bio/Technology 13 (2): 121-137. doi:10.1007/s11157-014-9332-8.

Tsing, Anna Lowenhaupt. 2017. The Mushroom at the End of the World: On the Possibility of Life in Capitalist Ruins. Princeton, NJ: Princeton University Press.

Tsosie, Rebecca. 2015. "Indigenous Peoples and the Ethics of Remediation: Redressing the Legacy of Radioactive Contamination for Native Peoples and Native Lands." Santa Clara Journal of International Law 13 (1): 203-272. https://digitalcommons.law.scu.edu/scujil/vol13/iss1/10.

Tuler, Seth P., Thomas P. Seager, Rebecca Kay, and Igor Linkov. 2007. "The Bouchard-120 and Chalk Point Spill Responses: Objectives and Performance Metrics." In Environmental Security in Harbors and Coastal Areas: Management Using Comparative Risk Assessment and Multi-Criteria Decision Analysis, ed. Igor Linkov, Gregory A. Kiker, and Richard J. Wenning, 175-191. Dordrecht: Springer Netherlands.

Ulibarri, Nicola, Cameron L. Tracy, and Ryan J. McCarty. 2020. “Cleanup and Complexity: Nuclear and Industrial Contamination at the Santa Susana Field Laboratory, California." Environmental Management 65: 257-271. doi:10.1007/s00267-019-01239-7.

Ureta, Sebastian. 2016. "Caring for Waste: Handling Tailings in a Chilean Copper Mine." Environment and Planning A 48 (8): 1532-1548. doi:10.1177/0308518x16645103. 
Van Horn, Carl E., and Yvonne Chilik. 1988. "How Clean Is Clean? A Case Study of the Nation's No. 1 Superfund Toxic Dump." Environmental Impact Assessment Review 8 (2): 133-148. doi:10.1016/ 0195-9255(88)90073-X.

Waterton, Claire. 2017. "Indeterminacy and More-Than-Human Bodies: Sites of Experiment for Doing Politics Differently." Body and Society 23 (3): 102-129. doi:10.1177/1357034X17716522.

Waterton, Claire, Stephen Maberly, Lisa Norton, Judith Tsouvalis, Nigel Watson, and Ian Winfield. 2015. "Opening up Catchment Science: An Experiment in Loweswater, Cumbria, England." In Catchment and River Basin Management: Integrating Science and Governance, ed. Laurence Smith, Keith Porter, Kevin Hiscock, Mary Jane Porter and David Benson, 183-206. London: Earthscan.

Wedding, G. Christopher, and Douglas Crawford-Brown. 2007. "Measuring Site-Level Success in Brownfield Redevelopments: A Focus on Sustainability and Green Building." Journal of Environmental Management 85: 483-495. doi:10.1016/j.jenvman.2006.10.018.

Williams, Brett. 2001. "A River Runs Through Us." American Anthropologist 103 (2): 409-431. doi:10 .1525/aa.2001.103.2.409. 